\title{
Variação sazonal do fitoplâncton e parâmetros ambientais no Canal do Rio Palmital, Baía da Babitonga, Sul do Brasil
}

\author{
Seasonal variation of phytoplankton and environmental parameters in the channel of \\ the river Palmital, Babitonga Bay, Southern Brazil
}

\author{
Rafael Antonio Parizzi, José Maria Souza-Conceição, Luciano Lorenzi, Guilherme A. D. F. Mira, \\ Mariana S. Oortman, Gabriel Conorath, Edinéia Bieger \\ Universidade da Região de Joinville, UNIVILLE, Joinville - SC - Brasil
}

\begin{abstract}
Resumo
Estudos de potencial produtivo, principais grupos de fitoplâncton, variações espaço-sazonais e fatores ambientais determinantes são essenciais na elaboração de estratégias de conservação de estuários. Este trabalho teve o objetivo de analisar a variação espaço-sazonal do fitoplâncton e sua interação com os parâmetros ambientais no canal do rio Palmital (baía da Babitonga-SC). Na área de canal do rio, foram realizadas 4 campanhas (maio, agosto, novembro de 2009; e fevereiro de 2010) em três pontos. Os estratos de superfície e de fundo foram analisados quanto à composição e abundância do fitoplâncton, nutrientes dissolvidos, temperatura, salinidade e transparência. O fitoplâncton teve como componentes dominantes as diatomáceas penadas e cêntricas, seguidas por dinoflagelados e cianofíceas. As espécies Skeletonema costatum e Odontella sinensis foram as mais abundantes, principalmente no verão. Outros gêneros numericamente importantes foram Coscinodiscus, Cyclotella, Thalassionema, Navicula, Pleurosigma, Actinoptychus e Diploneis. Grande quantidade de táxons bênticos registrados neste estudo deve-se à baixa profundidade associada à circulação local. No verão, ocorreu um "bloom" de S. costatum. Correlações significativas entre as variáveis ambientais e a abundância do fitoplâncton foram observadas neste trabalho pioneiro na área do rio Palmital, o que sugere mais estudos.
\end{abstract}

Palavras-chave: abundância, microalgas, estuário, rio, Santa Catarina

\begin{abstract}
Studies on potential production, spatial and seasonal variations, main groups of phytoplankton and determinant environmental conditions are essential for developing strategies for the conservation of estuaries. This study aimed to analyze the spatial and seasonal variation of phytoplankton and their interaction with environmental parameters in the Palmital river channel (Babitonga Bay - SC). In the area of the river channel, it was conducted four campaigns (May, August, November 2009, and February 2010) at three points. Both surface and bottom layers of water were analyzed for composition and abundance of phytoplankton, dissolved nutrients and physico-chemical parameters. Pennate and centric diatoms were the dominant components of the phytoplankton community, followed by dinoflagellates and cyanobacteria. Skeletonema costatum and Odontella sinensis were the most abundant species, especially in summer. Other genera were numerically important: Coscinodiscus, Cyclotella, Thalassionema, Navicula, Pleurosigma, Actinoptychus and Diploneis. Large amount of benthic taxa recorded in this study is due to the low depth associated with local circulation. In summer occurred a bloom of Skeletonema costatum. Significant correlations between the environmental variables and the phytoplankton abundance were observed in this pioneering work in the Palmital river area, suggesting further studies.
\end{abstract}

Keywords: abundance, microalgae, estuary, river, Santa Catarina 


\section{Introdução}

Estuários constituem corpos d'água semifechados com conexão livre para o mar aberto, onde a água do mar é gradativamente diluída pela drenagem continental, e apresenta características físicas, químicas e biológicas exclusivas (KOLASA \& ZALEWSKI, 1995). São considerados "berçários da vida marinha" por abrigarem diversas espécies em estágio inicial de desenvolvimento, decorrente da sua reduzida salinidade, disponibilidade de alimento e heterogeneidade de habitats (AVELINE, 1980; ODUM, 1983). Por sua localização entre o ambiente terrestre e o marinho, assim como em função dos diversos recursos que oferecem, os estuários vem sendo convertidos em locais de desenvolvimento urbano, industrial e recreacional, sujeitos a forte pressão antrópica, como a descarga de efluentes industriais, urbanos e produtos agrícolas. Tais sistemas atuam como as principais fontes de nutrientes para a região costeira, pois recebem e concentram grande quantidade de materiais originados de sua bacia de drenagem, além das contribuições antrópicas significativas. Por esse motivo, são caracterizados como um dos ecossistemas mais produtivos do mundo, com elevados teores de biomassa e elevada taxa de produção primária (BRAGA et al., 2000; LALLI \& PARSONS, 1997).

Dentre os produtores primários dos sistemas aquáticos marinhos, o fitoplâncton constitui o principal componente. Através de relações tróficas, a energia e a matéria destes organismos são transferidas aos demais elos da cadeia alimentar, produzindo matéria orgânica e dióxido de carbono, além de servir como fonte de oxigênio, necessário para o metabolismo dos consumidores (LALLI \& PARSONS, 1997). O desenvolvimento da comunidade fitoplanctônica está associado a diversos fatores dos ambientes terrestre e marinho, dentre os quais se destacam a pluviosidade, o aporte de nutrientes, a profundidade da zona eufótica e a circulação da coluna d'água. Dessa forma, o complexo comportamento e circulação dos estuários propiciam a ocorrência de gradientes e variações temporais em suas propriedades abióticas que, por sua vez, influenciam a dinâmica do fitoplâncton, nas taxas de produtividade primária, nas variações espaciais e sazonais, na composição e biomassa (BRANDINI \& THAMM, 1994). A determinação dos componentes da comunidade fitoplanctônica tem fundamental importância para a avaliação do estado de conservação do ambiente, uma vez que respondem rapidamente às condicionantes físicas e químicas (CERVETO et al., 2002).

Localizada no norte do litoral catarinense $\left(26^{\circ} 02^{\prime}-26^{\circ} 28^{\prime} \mathrm{S}\right.$ e $\left.48^{\circ} 28^{\prime}-48^{\circ} 50^{\prime} \mathrm{W}\right)$, a baía da Babitonga compõe o maior complexo estuarino do estado. Totaliza $130 \mathrm{~km}^{2}$, possui profundidade média de 6 metros e um volume aproximado de $7,8 \times 10^{8} \mathrm{~m}^{3}$. O clima da região é caracterizado por inverno e verão nitidamente definidos ao longo do ano. O estuário possui caráter mixohalino, com águas da plataforma continental misturando-se com a drenagem continental, caracterizando-o como homogêneo (IBAMA, 1998; DENIT/IME, 2004). Seu entorno é rodeado por florestas de manguezal e importantes remanescentes de mata atlântica e restinga (FATMA, 2002), considerados como fontes de nutrientes para a coluna d'água. A baía da Babitonga apresenta um complexo que pode ser dividido em três grandes segmentos: a região do canal do Linguado, que contorna a ilha de São Francisco do Sul em sua porção sul; o corpo central da baía; e o canal do Palmital, região mais interna ao norte, sob influência dos rios Palmital e Cubatão e com características estuarinas em grande parte de sua extensão (CREMER et al., 2006). Possui em seu entorno os municípios de Joinville, Araquari, São Francisco do Sul, Itapoá e Garuva, que juntos abrigam mais de 500.000 habitantes e o maior parque industrial do estado. Conforme SOUZA-CONCEIÇÃO (2008), a área desta baía tem grande importância ecológica, econômica e social, porém já apresenta sinais de impactos gerados pela forte pressão antrópica.

Apesar da complexidade deste ecossistema e de sua importância ecológica, os trabalhos científicos desenvolvidos na baía da Babitonga ainda são muito escassos, especialmente na área do canal do rio Palmital. Para a compreensão do estuário como ambiente dinâmico, é fundamental o entendimento dos mecanismos que geram esta variabilidade. Estudos relacionados ao potencial produtivo e aos principais grupos de produtores primários planctônicos, variações em sua composição e fatores ambientais determinantes são essenciais para a elaboração de estratégias adequadas de conservação, manejo e utilização racional dos recursos deste importante ecossistema. Neste contexto, este trabalho teve como objetivo analisar a composição taxonômica do fitoplâncton e a variação espaço-sazonal da biomassa, das concentrações de nutrientes dissolvidos e dos parâmetros físicos e químicos no canal do rio Palmital (baía da Babitonga).

\section{Materiais e métodos}

\subsection{Obtenção e análise das amostras.}

Na área do canal do rio Palmital foram realizadas amostragens em maio, agosto e novembro de 2009 (outono, inverno e primavera, respectivamente), e fevereiro de 2010 (verão). Nestas campanhas foram coletadas amostras de água de superfície e fundo com uma garrafa modelo Van Dorn em três pontos ao 
longo do canal (Figura 1). A profundidade média nos pontos amostrais $1\left(26^{\circ} 11^{\prime} 06,36^{\prime \prime} \mathrm{S}-48^{\circ} 45^{\prime} 44,21^{\prime \prime} \mathrm{W}\right)$, $2\left(26^{\circ} 12^{\prime} 26,33^{\prime \prime} \mathrm{S}-48^{\circ} 45^{\prime} 51,54^{\prime \prime} \mathrm{W}\right)$ e $3\left(26^{\circ} 13^{\prime} 35,65^{\prime \prime}\right.$ $\left.S-48^{\circ} 45^{\prime} 38,45^{\prime \prime} \mathrm{W}\right)$ correspondeu a 4,10 e 7 metros, respectivamente.

Para determinar as variações da concentração de nutrientes, as amostras de água foram armazenadas em frascos plásticos e mantidas em baixa temperatura até a análise. Em laboratório foram filtradas em filtros de $0,45 \mu \mathrm{m}$ de abertura de poro através de uma bomba a vácuo e adicionados os respectivos reagentes para a determinação de amônio $\left(\mathrm{NH}_{3}\right)$, nitrato $\left(\mathrm{NO}_{3}\right)$, nitrito $\left(\mathrm{NO}_{2}\right)$, fosfato $\left(\mathrm{PO}_{4}\right)$ e silicato $\left(\mathrm{Si}(\mathrm{OH})_{4}\right)$, pelo método colorimétrico em um multianalisador Policontrol Smart 2. Os valores de temperatura $\left({ }^{\circ} \mathrm{C}\right)$ e salinidade foram determinados em campo por meio de um multianalisador modelo Hanna. A transparência da água foi determinada em centímetros com um disco de Secchi.
Para determinar as concentrações de clorofila, foram filtradas alíquotas de $100 \mathrm{~mL}$ em um sistema de filtração (Whatman) com filtros modelo AP40 de fibra de vidro com 25 milímetros de diâmetro e 1,2 $\mu$ m de abertura de poro. Para a extração dos pigmentos, as amostras permaneceram em repouso no freezer por 24 horas em tubos de ensaio contendo acetona a 90 $\%$ e posteriormente transferidas para cubetas onde se procedeu a leitura no fluorímetro Turner Designs modelo Trilogy.

Na análise quali-quantitativa do fitoplâncton, as amostras de água foram armazenadas em frascos de vidro cor ambar com solução de Lugol a $2 \%$. Em laboratório, uma alíquota de $5 \mathrm{~mL}$ permaneceu 24 horas em uma câmara de sedimentação para posterior observação em microscópio invertido, sendo identificados os táxons e quantificado o número total de indivíduos por mililitro. A identificação dos organis-



Figura 1: Localização do estuário da baía da Babitonga no litoral norte catarinense e disposição dos pontos amostrais na área de estudo. Fonte: Google Earth. 
mos ao menor táxon possível foi realizada através de referências especializadas, tais como Carmelo (1997) e Steidinger \& Jangen (1996).

\section{Análise dos dados}

As variações dos valores médios obtidos para os parâmetros do fitoplâncton e ambientais foram apresentadas em gráficos para a observação das tendências entre pontos amostrais e épocas. A relação entre os parâmetros biológicos e os físicos e químicos foram testadas por meio da análise de correlação de Spearman, na qual as relações foram consideradas significativas ao nível $p<0,05$. Uma Análise de Componentes Principais (ACP) também foi realizada sobre os parâmetros bióticos e abióticos para melhor explicar os padrões de variação espaço-sazonais observados (CLARKE \& WARWICH, 2001). Ambas análises foram realizadas no Programa Statistica 5.0 para Windows (STATSOFT, 1995).

\section{Resultados}

\subsection{Parâmetros físicos e químicos.}

A temperatura da água variou sazonalmente, com diferença de $11,2{ }^{\circ} \mathrm{C}$ entre a maior e menor média. As médias para as estações do ano revelaram dois períodos característicos na área, formados por outono/inverno e primavera/verão. Espacialmente na área ocorreu pouca variação da temperatura (Fig. 2).

A salinidade teve variação sazonal e espacial mais definida, ocorrendo um gradiente de variação entre pontos amostrais e estações. As maiores médias de salinidade foram registradas no outono e no ponto 3, e as menores no verão e no ponto 1 (Fig. 2). A transparência da água foi menor na primavera e no verão, e entre os pontos foi maior no ponto 2 , de maior profundidade (Fig. 2).

As concentrações de nutrientes dissolvidos ocorreram em geral com elevação em outono ou inverno, e menores valores nas demais estações. Um
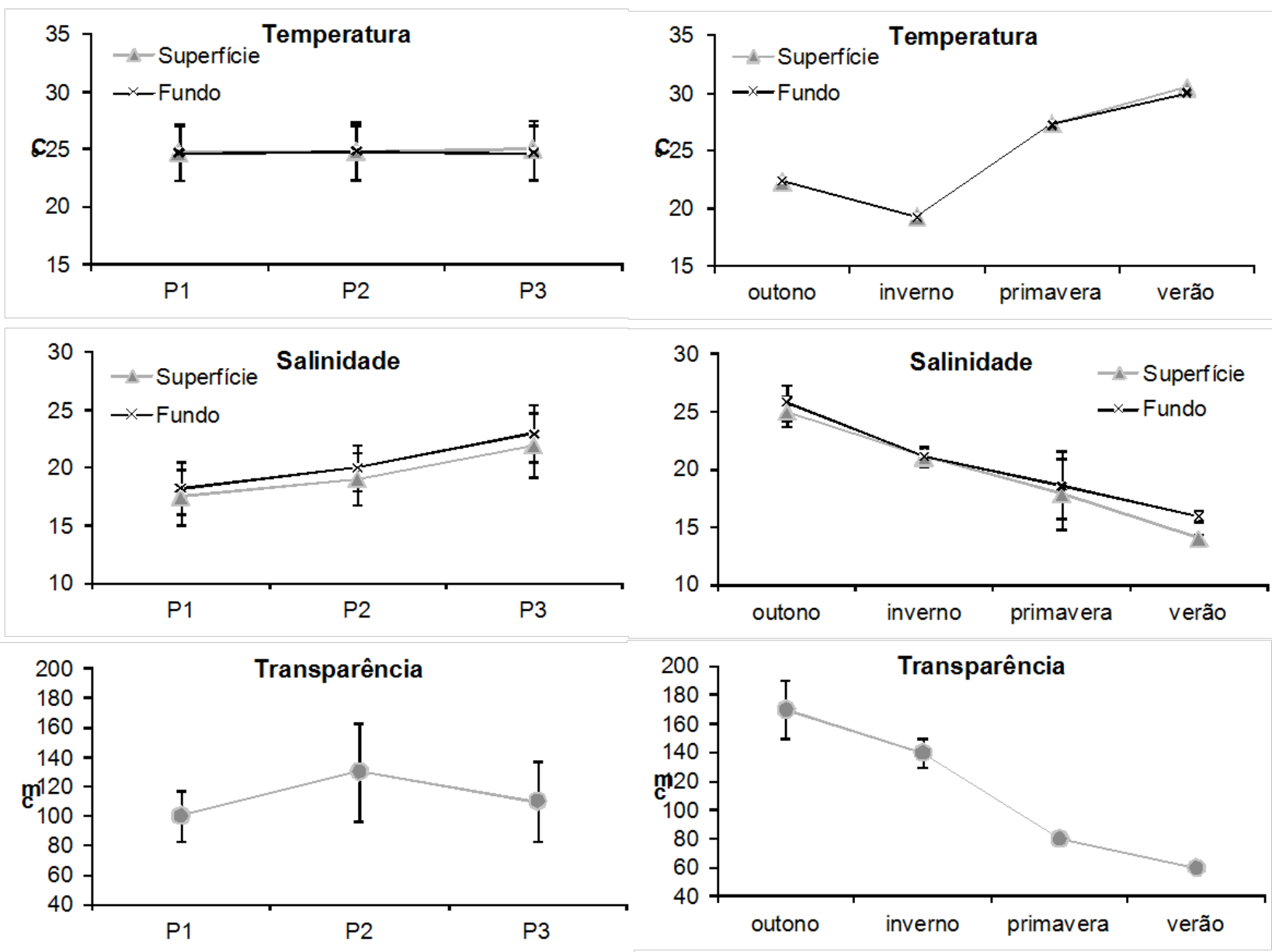

Figura 2: Variações (médias \pm erro padrão) de temperatura, salinidade e transparência entre os pontos amostrais e estações do ano no canal do rio Palmital. 

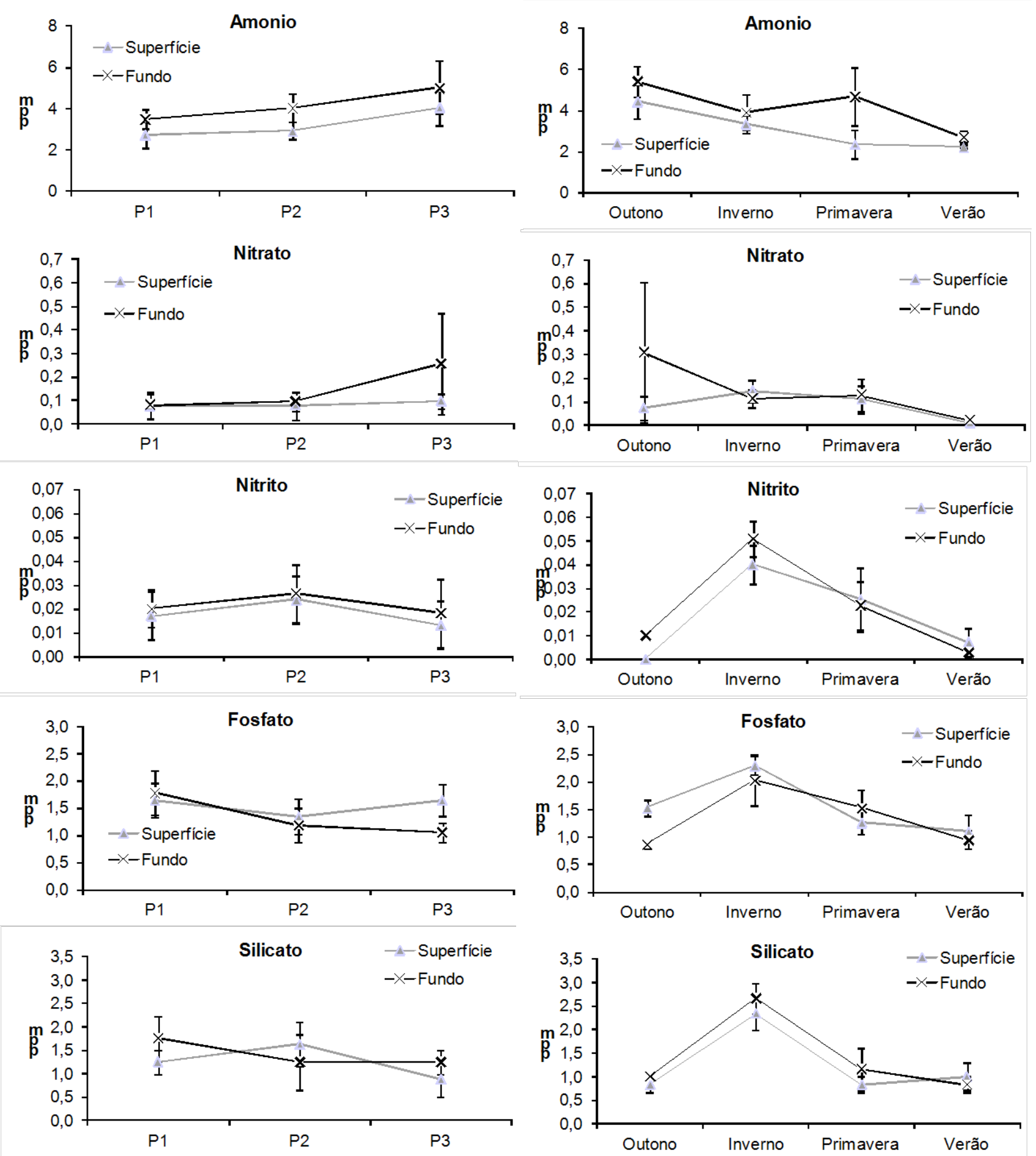

Figura 3: Variação sazonal (médias \pm erro padrão) da concentração de nutrientes dissolvidos no canal do rio Palmital. 

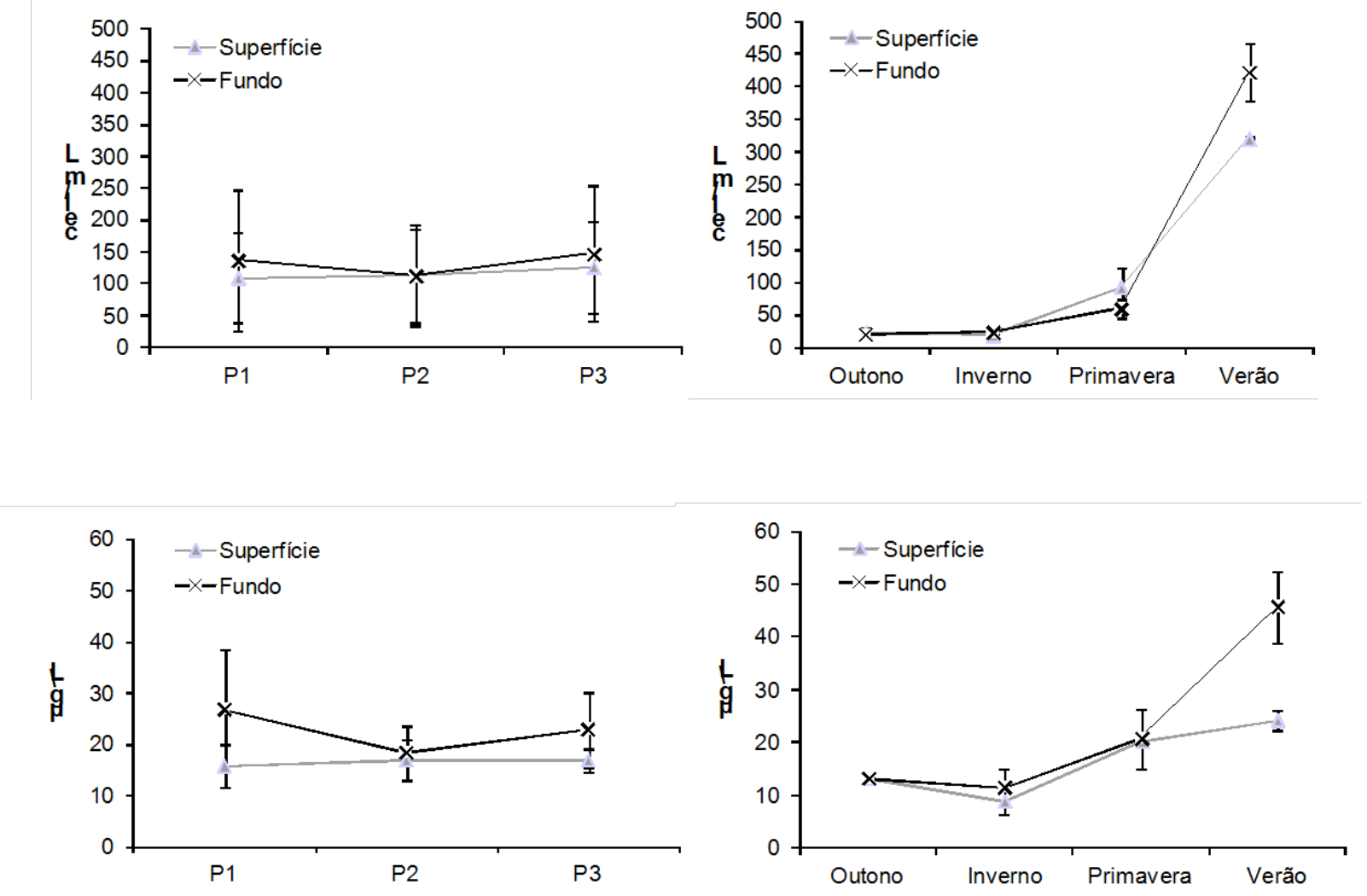

Figura 4: Variação espacial e sazonal (médias \pm erro padrão) da clorofila a em microgramas por litro ( $\mu \mathrm{g} / \mathrm{L})$ no canal do rio Palmital.

gradiente decrescente de concentrações foi comum da primavera para o verão. Espacialmente, a área de estudo foi homogênea, com pequena variação entre as áreas de cada um dos pontos amostrais (Fig. 3).

O teor de amônio aumentou em direção ao ponto 3, porém, no geral, manteve-se elevado durante todo o período de estudo. Maiores valores ocorreram no outono, com média de 4,65 ppm, e menores no verão, com média de 2,48 ppm. As concentrações de nitrato e nitrito tiveram maior variação entre estratos no ponto 3, nos demais pontos as tendências foram similares. Sazonalmente, a maior concentração ocorreu no outono para nitrato e no inverno para nitrito (Fig. 3).

O fosfato teve pouca variação entre os pontos amostrais. Entre as épocas, o maior valor ocorreu no inverno, com média de 2,16 ppm, e no verão ocorreram as menores concentrações, média de 1,0ppm. A concentração de silicato teve maior valor médio no ponto $1 \mathrm{e}$, ao longo do ano, foi maior no inverno, com média de 2,5 ppm. Nas outras estações, os valores médios foram próximos a 1,0 ppm (Fig. 3).

\section{Fitoplâncton}

A abundância do fitoplâncton variou pouco entre os pontos amostrais, porém foi maior nos pontos
1 e 3 no fundo. Sazonalmente, a abundância foi maior em primavera e verão, mas notavelmente maior no verão, tanto em superfície quanto no fundo (Figura 4). A clorofila teve distribuição com tendência espaço-sazonal similar a abundância (Figura 5), porém com diferenças entre superfície e fundo mais evidentes.

Figura 4: Variação espacial e sazonal (médias \pm erro padrão) da abundancia do fitoplâncton em células por mililitro (cel/mL) no canal do rio Palmital.

Um total de 68 táxons foram identificados, um Cianophyceae, 9 Dinophyceae, 58 Bacillariophyceae e 1 Chrysophyceae. O número total de células de fitoplâncton por mililitro no canal do rio Palmital variou entre 111,6 (outono) e 1871,6 (verão). A elevada biomassa registrada em primavera e verão foi resultado da alta densidade das espécies Skeletonema costatum e Odontella sinensis (Tabela 1).

Bacillariophyceae foi o grupo mais representativo em abundância e composição, com 58 táxons. Os gêneros mais comuns foram: Chaetoceros, Navicula, Odontella, Pleurosigma, Skeletonema, Pseudo-nitzschia, Thalassionema e Coscinodiscus. O segundo grupo mais representativo foi Dinophyceae com 9 táxons, sendo Ceratium, Noctiluca e Protoperidiniun os gêneros mais comuns (Tabela 1). 
Tabela 1: Lista dos táxons fitoplanctônicos e variação sazonal da densidade celular (células/mL) registrados no canal do rio Palmital.

\begin{tabular}{|c|c|c|c|c|}
\hline Táxons & Outono & Inverno & Primavera & Verão \\
\hline \multicolumn{5}{|l|}{ Bacillariophyceae } \\
\hline Actinoptychus senarius & 1,67 & - & - & 0,60 \\
\hline Actinoptychus sp. & 0,80 & 2,03 & 3,93 & 0,80 \\
\hline Amphora sp. & - & - & 2,57 & 3,57 \\
\hline Asterionellopsis glacialis & - & - & - & 0,20 \\
\hline Bacillaria sp. & - & - & - & 0,20 \\
\hline Bacteriastrum sp. & - & 0,20 & 0,20 & 0,20 \\
\hline Chaetoceros affinis & 0,03 & - & - & - \\
\hline Chaetoceros decipiens & - & 0,03 & - & - \\
\hline Chaetoceros lorenzianus & - & - & - & 2,40 \\
\hline Chaetoceros spp. & 0,03 & 6,40 & 12,87 & 20,13 \\
\hline Cyclotella sp. & 1,00 & 5,20 & 14,50 & 14,20 \\
\hline Corethron sp. & - & 0,20 & - & - \\
\hline Coscinodiscus granni & - & - & 0,03 & - \\
\hline Coscinodiscus wailesii & - & - & - & 0,03 \\
\hline Coscinodiscus spp. & 11,00 & 14,30 & 24,20 & 15,40 \\
\hline Diatomácea & 21,63 & 32,66 & 66,83 & 53,10 \\
\hline Dictyocha staurodon & 0,43 & 2,00 & 1,30 & 0,80 \\
\hline Diploneis bambus & - & 0,03 & - & - \\
\hline Diploneis sp. & 0,73 & 5,23 & 5,43 & 7,23 \\
\hline Ditylum sp. & 0,20 & 0,43 & - & 1,43 \\
\hline Gyrosigma sp. & 2,63 & - & - & 1,27 \\
\hline Grammatophora sp. & - & 0,20 & - & 0,50 \\
\hline Guinardia striata & 0,03 & - & - & - \\
\hline Helicotheca tamesis & - & - & 1,60 & 0,83 \\
\hline Hemiaulus sp. & - & 0,20 & - & - \\
\hline Hemiaulus membranaceus & - & - & 0,03 & - \\
\hline Hemiaulus sinensis & 0,03 & - & - & - \\
\hline Lyrella sp. & - & - & 0,40 & - \\
\hline Melosira sp. & - & - & 8,03 & 24,50 \\
\hline Navicula sp. & 17,76 & 7,27 & 9,47 & 29,07 \\
\hline Nitzschia longissima & - & - & 1,67 & 9,70 \\
\hline Nitzschia sp. & - & - & 19,40 & 2,40 \\
\hline Odontella aurita & - & - & - & 0,60 \\
\hline Odontella mobiliensis & - & 0,03 & - & - \\
\hline Odontella sinensis & 0,63 & 1,67 & 70,83 & 180,13 \\
\hline Odontella sp. & - & 0,40 & - & - \\
\hline Pleurosigma sp. & 11,13 & 1,70 & 7,20 & 17,23 \\
\hline Pseudo-nitzschia sp. 1 & 2,40 & 1,00 & 0,80 & 6,30 \\
\hline Pseudo-nitzschia sp. 2 & 4,27 & 2,03 & 3,60 & 9,83 \\
\hline Pseudo-nitzschia sp. 3 & 1,60 & 0,40 & 1,20 & 0,53 \\
\hline Rhabdonema sp. & - & 0,23 & - & - \\
\hline Rhizosolenia imbricata & - & - & - & 0,20 \\
\hline Rhizosolenia setigera & - & - & - & 2,13 \\
\hline Skeletonema costatum & 11,47 & 18,20 & 91,60 & $1.379,00$ \\
\hline Surirella sp. & 2,07 & 0,40 & 0,40 & 0,03 \\
\hline Thalassionema frauenfeldii & - & - & - & 0,30 \\
\hline Thalassionema nitzschioides & 0,20 & - & - & 18,47 \\
\hline Thalassionema sp. & 0,20 & 2,63 & 22,63 & 35,87 \\
\hline Thalassiosira spp. & - & - & 0,03 & - \\
\hline Thalassiothrix sp. & 1,77 & 0,10 & - & 1,03 \\
\hline Triceratium sp. & 3,50 & - & - & 0,60 \\
\hline Tryblionella sp. & - & - & 2,23 & 3,53 \\
\hline Total Bacillariophyceae & 97,22 & 105,19 & 375,39 & $1.849,19$ \\
\hline \multicolumn{5}{|l|}{ Dinophyceae } \\
\hline Alexandrium sp. & - & 0,60 & 0,20 & - \\
\hline Ceratium lineatum & 0,20 & - & 0,03 & - \\
\hline Ceratium sp. & - & - & 0,20 & 0,40 \\
\hline Dinoglagelado & 4,60 & 6,23 & 9,23 & 11,60 \\
\hline Dinophysis sp. & - & - & - & 1,00 \\
\hline Noctiluca scintillans & 5,67 & 5,60 & 0,80 & 2,20 \\
\hline Protoperidinium sp. & 0,80 & 0,20 & - & 1,03 \\
\hline Total Dinophyceae & 11,27 & 12,63 & 10,47 & 18,43 \\
\hline \multicolumn{5}{|l|}{ Cianophyceae } \\
\hline Cianophyceae & 3,27 & 4,80 & 2,90 & 4,00 \\
\hline Oscillatoria sp. & - & - & 0,03 & - \\
\hline Total Cianophyceae & 3,27 & 4,80 & 2,93 & 4,00 \\
\hline TOTAL cél/mL & 111,75 & 122,63 & 388,79 & $1.871,63$ \\
\hline
\end{tabular}




\section{Correlações e Análise de Componentes Principais (ACP)}

A análise de correlações de Spearman indicou relações significativas entre as variáveis bióticas e abióticas estudadas. Dessa forma, como resultado, foram assinaladas correlações significativas positivas e/ou negativas $(\mathrm{p}<0,05)$ para a temperatura de superfície e fundo, salinidade de superfície e fundo, transparência, clorofila $a$ de superfície e fundo, amônio de superfície e fundo, fosfato de superfície, nitrato de superfície, nitrito de fundo, silicato de fundo, células totais por mililitro de superfície e fundo (Tabela 2).

A análise de componentes principais (ACP) realizada sobre os parâmetros bióticos e abióticos (abundância do fitoplâncton, temperatura, salinidade, transparência e nutrientes dissolvidos) revelou padrões espaço-sazonais no canal. O resultado confirmou importante relação entre os parâmetros analisados, sendo obtida elevada explicação da variância dos dados. Nesse sentido, as duas componentes somadas corresponderam a 72,6\% da variância. Na distribuição das amostras, observam-se dois conjuntos (eixo horizontal), verão/primavera e inverno/outono. Separados como extremos estão verão e inverno, e como épocas de condições intermediárias primavera e outono. Os pontos amostrais em cada época seguem a tendência de gradiente espacial (eixo vertical), entre os extremos de condições 1 e 3 , sendo 2 mais similar ao ponto 1 (Fig. 5).

Tabela 2. Resultados da análise de correlações de Spearman entre os parâmetros abióticos e bióticos no canal do rio Palmital.

\begin{tabular}{lcccc}
\hline & Clo-aSup & Clo-aFund & CelTotSup & CelTotFund \\
\hline $\mathrm{T}^{\circ}$ CSup & $0,896^{*}$ & $0,806^{*}$ & $0,799^{*}$ & $0,654^{*}$ \\
T ${ }^{\circ}$ CFund & $0,875^{*}$ & $0,782^{*}$ & $0,772^{*}$ & $0,705^{*}$ \\
SalSup & $-0,634^{*}$ & $-0,713^{*}$ & $-0,706^{*}$ & $-0,725^{*}$ \\
SalFund & $-0,655^{*}$ & $-0,706^{*}$ & $-0,678^{*}$ & $-0,704^{*}$ \\
Transp & $-0,764^{*}$ & $-0,782^{*}$ & $-0,898^{*}$ & $-0,901^{*}$ \\
AmonSup & $-0,827^{*}$ & $-0,818^{*}$ & $-0,706^{*}$ & $-0,606^{*}$ \\
AmonFund & $-0,515$ & $-0,601^{*}$ & $-0,517$ & $-0,473$ \\
FosfSup & $-0,775^{*}$ & $-0,564$ & $-0,504$ & $-0,453$ \\
FosfFund & $-0,218$ & $-0,126$ & $-0,070$ & 0,079 \\
NitraSup & $-0,672^{*}$ & $-0,585^{*}$ & $-0,364$ & $-0,288$ \\
NitraFund & $-0,350$ & $-0,343$ & $-0,455$ & $-0,224$ \\
NitriSup & $-0,239$ & $-0,179$ & 0,004 & 0,179 \\
NitriFund & $-0,623^{*}$ & $-0,546$ & $-0,588^{*}$ & $-0,472$ \\
SiliSup & $-0,339$ & $-0,242$ & $-0,209$ & $-0,040$ \\
SiliFund & $-0,587^{*}$ & $-0,360$ & $-0,316$ \\
\hline
\end{tabular}

(*) Correlações significativas ao nível de $\mathrm{p}<0,05$.

$\mathrm{T}^{\circ} \mathrm{C} \mathrm{S}$ (Temperatura superfície); $\mathrm{T}^{\circ} \mathrm{C}$ F (Temperatura fundo); Sal S (Salinidade superfície); Sal F (Salinidade fundo); Transp (Transparência); Clo-a S (Clorofila a superfície); Clo-a F (Clorofila a fundo); Amon S (Amônio superfície); Amon F (Amônio fundo); Fosf S (Fosfato superfície); Fosf F (Fosfato fundo); Nitra S (Nitrato superfície); Nitra F (Nitrato fundo); Nitri S (Nitrito superfície); Nitri F (Nitrito fundo); Sil S (Silicato superfície); Sil F (Silicato fundo); $N^{\circ}$ Tot S (n total de células por mililitro na superfície); $\mathrm{N}^{\circ}$ Tot F (n total de células por mililitro no fundo) 


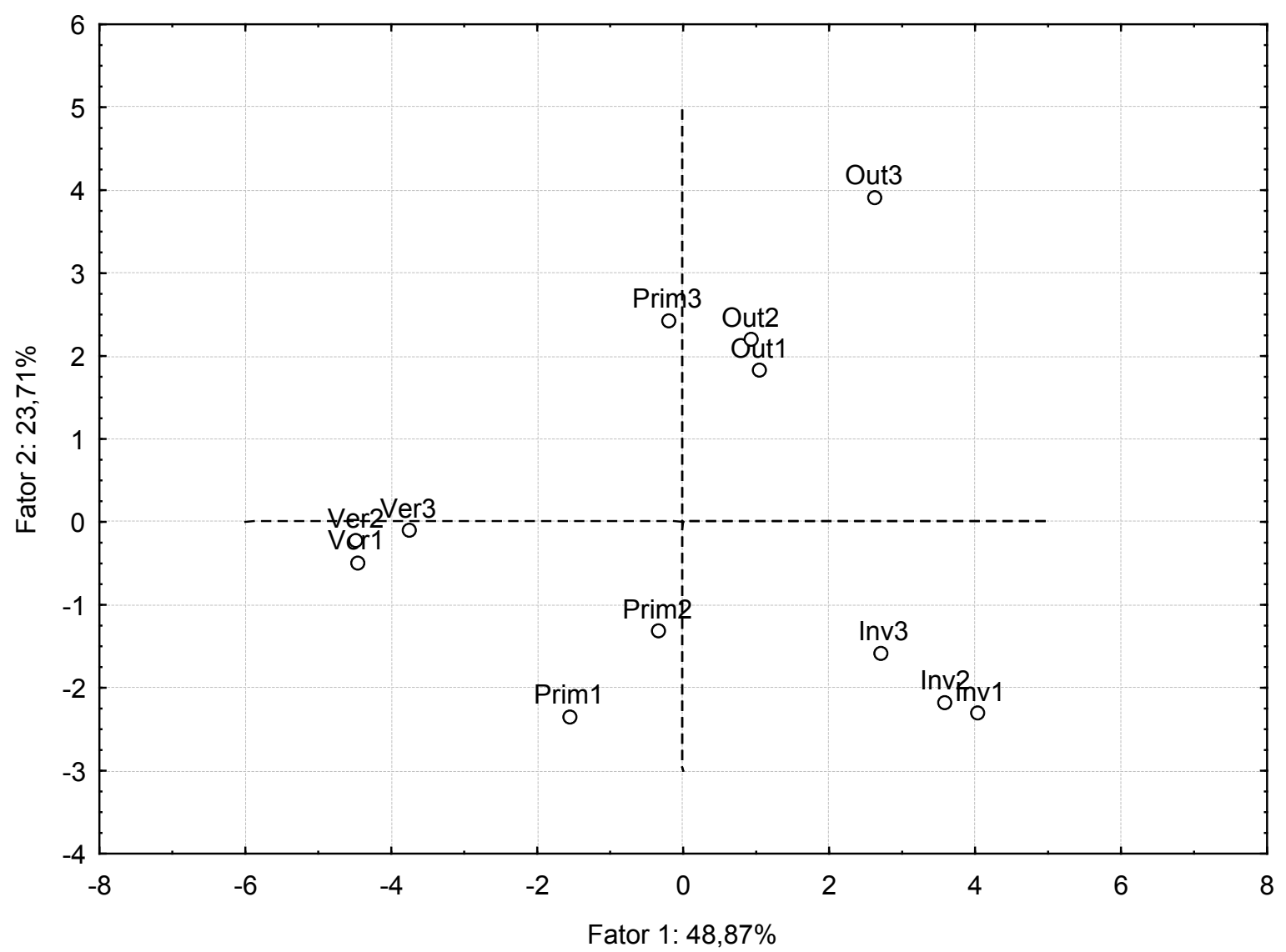

Figura 5: Resultado da Análise de Componentes Principais (ACP) sobre os parâmetros bióticos e abióticos analisados espaço-sazonalmente. Os códigos referem-se aos três pontos (1, 2 e 3) e as quatro épocas de amostragem (Out: outono, Inv: inverno, Prim: Primavera, Ver: verão).

\section{Discussão}

A temperatura foi espacialmente homogênea e variou sazonalmente com tendência geral inversa à da salinidade, ocorrendo dois períodos definidos ao longo do ano (outono-inverno e primavera-verão). O comportamento espaço-sazonal desta variável corrobora os resultados de CAMACHO \& SOUZA-CONCEIÇÃO (2007) e COSTA \& SOUZA-CONCEIÇÃO (2009) no mesmo complexo estuarino. A salinidade variou, espacialmente, com maiores valores no ponto 3 , que foi mais influenciado pela água estuarina, e menores no ponto 1, que esteve sob maior influência do aporte continental. Um gradiente decrescente foi claramente observado em outono e primavera no sentido montante, resultado da mistura com a água proveniente da drenagem continental. Sazonalmente, os menores valores de salinidade foram registrados na primavera e verão, refletindo a elevação dos índices pluviométricos. Nestes ambientes, a dinâmica dos processos que determinam os parâmetros físicos e químicos é fortemente influenciada pela ação da maré, sendo condicionante para a distribuição da temperatura, salinidade, material particulado em suspensão, assim como a penetração de luz. A variabilidade espacial torna-se mais pronunciada quando os aportes de água doce são significantes, com a formação de gradientes de salinidade bem definidos (LAPOINTE \& CLARKE, 1992). Este sinergismo produz mudanças acentuadas nas associações biológicas, tais como aquelas dos organismos fitoplanctônicos, em escalas de tempo de ciclos de maré (horas), dias e sazonais (RAYMONT, 1980; McLUSKY, 1994; LALLI \& PARSONS, 1997).

A elevada concentração de material particulado em suspensão, indicada pela acentuada queda nos valores de transparência na primavera e verão, em especial no ponto 1 , associa-se ao aporte continental. Este aporte atua no transporte de grandes quantidades de material particulado, podendo atuar tanto como fator limitante no desenvolvimento do fitoplâncton, quanto estimular o seu florescimento (LALLI \& PAR- 
SONS, 1997), uma vez que proporciona nutrientes dissolvidos. Segundo BRANDINI (2000) e CAMACHO \& SOUZA-CONCEIÇÃO (2007), os menores valores de transparência nas áreas mais internas da baía das Laranjeiras (PR) e da Babitonga (SC) devem-se também a pouca profundidade, que favorece a ressuspensão de sedimentos durante períodos de maior turbulência.

As maiores concentrações de amônio foram registradas no outono. Em área mais próxima da barra da baía da Babitonga, CAMACHO (2006) e SOUZA-CONCEIÇÃO (2008) descreveram maiores concentrações no verão, provavelmente pela diferença de localização no estuário e, consequentemente, de configuração física do ambiente. O alto teor de amônio registrado neste estudo indicou que este ecossistema recebe grande aporte de matéria orgânica, uma vez que sofre influência direta das atividades antrópicas do município de Joinville através do rio Cubatão, recebendo esgoto doméstico e resíduos industriais. $\mathrm{O}$ rio Cubatão deságua no canal do rio Palmital, que por sua vez recebe grande aporte de Garuva, município que possui importante atividade agrícola e carência no tratamento de esgotos (CREMER et al., 2006). Altas concentrações de amônio foram igualmente registradas em ambientes sob grande influência de lançamento de esgotos domésticos e próximos a intensas atividades agrícolas, como no estuário da Barra das Jangadas (PE) por Delgado-Noriega et al. (2005) e na Lagoa dos Patos (RS) por SEELIGER et al. (1998).

As concentrações mais elevadas de nitrato e nitrito ao longo do ano corroboram o estudo de Camacho (2006) e SOUZA-CONCEIÇÃO (2008), sendo que este acúmulo deve-se principalmente a processos de remineralização e à atividade fitoplanctônica reduzida, permitindo a estocagem. As menores concentrações registradas no verão indicaram maior consumo destes nutrientes.

De acordo com BRANDINI \& THAMM (1994), a dinâmica temporal do fosfato em ambientes estuarinos está relacionada principalmente a processos de circulação e ação da maré, da variação do aporte continental e ressuspensão de sedimentos. A grande quantidade de material particulado em suspensão pode ser considerada como um dos principais fatores responsáveis pelas concentrações de fosfato registradas neste trabalho, pois conforme Delgado-Noriega et al. (2005) existe relação direta entre o material particulado presente e o aumento deste nutriente. O silicato é utilizado pelas microalgas do grupo das diatomáceas e dos silicoflagelados para formação das suas frústulas, sendo o nutriente inorgânico que ocorre com maiores concentrações nos ambientes estuarinos, devido a sua origem terrígena (LALLI \& PARSONS, 1997). A maior concentração deste nutriente no inverno deve- -se, provavelmente, a menor pluviosidade e consumo biológico. No presente estudo, a elevada concentração de nutrientes registrada para o canal do rio Palmital é comparativamente maior que aquelas descritas em outros trabalhos realizados ao longo do estuário da baia da Babitonga (CAMACHO, 2006; CREMER et al. 2006; SOUZA-CONCEIÇÃO, 2008). Adicionalmente, outros trabalhos em estuários (BRANDINI, 2000; DELGADO-NORIEGA et al., 2005) confirmam o gradiente de concentrações mais elevadas nas áreas mais internas destes ecossistemas, mais próximas a drenagem continental.

A composição do fitoplâncton em sistemas estuarinos fornece indícios sobre o estado de conservação e eutrofização destes ambientes. Em locais afetados pela ação antrópica, ocorre o enriquecimento dos cursos d'água pela utilização de fertilizantes, compostos de nitrogênio e fósforo, pelo uso de detergentes fosfatados e pelos efluentes domésticos não tratados, provocando a eutrofização (BONEY, 1989). No canal do rio Palmital, o fitoplâncton esteve amplamente dominado por diatomáceas penadas e cêntricas, seguido por dinoflagelados e cianofíceas. O domínio de diatomáceas, observado durante todo o período de estudo, demonstra a capacidade do ambiente em proporcionar altas taxas de produtividade primária, alcançando elevados teores de biomassa, por exemplo, no verão. Conforme Raymont (1980) e LALLI \& PARSONS (1997), devido ao seu método reprodutivo de divisão assexuada, o grupo é representado em geral por táxons de crescimento muito rápido em condições favoráveis, sendo dominante em regiões tropicais e temperadas.

Skeletonema costatum e Odontella sinensis foram as mais abundantes e ocorreram em todas as épocas, principalmente no verão. Em estudo pretérito na baía da Babitonga, ao longo do ano, S. costatum não foi registrada apenas no verão, enquanto $O$. sinensis ocorreu em todo o período (CREMER et al., 2006). Os dados registrados no verão revelaram a ocorrência de um "bloom" fitoplanctônico, com a espécie $S$. costatum, atingindo elevada abundância na coluna d'água. A disparidade entre o presente estudo e o de CREMER et al. (2006) para S. costatum foi reflexo da localização diferenciada entre pontos amostrais e/ou de importantes ciclos interanuais da espécie, o que sugere a realização de trabalhos com maior abrangência espaço-temporal na área.

Na baía de Paranaguá, BRANDINI (2000), e no estuário de Cananéia, KUTNER (1972) também relacionaram a maior abundância de Skeletonema spp. ao período de maior precipitação e a grande dominância em áreas mais internas (com menores salinidades), o que corrobora o registrado no canal 
do rio Palmital. Segundo KUTNER (1972), S. costatum possui capacidade de reprodução muito rápida e se desenvolve até atingir esgotamento dos elementos nutritivos do meio, portanto sua capacidade de ser dominante no ambiente é maior do que das outras diatomáceas. Outros gêneros numericamente importantes foram Coscinodiscus, Cyclotella, Thalassionema, Navicula, Pleurosigma, Actinoptychus e Diploneis.

A grande quantidade de táxons do grupo das penadas bênticas encontradas neste estudo (e.g. Asterionella, Surirella, Grammatophora, Gyrosigma, Navicula, Nitzschia, Pleurosigma e Thalassionema) deve-se a baixa profundidade, que favorece a ressuspensão de sedimento pelo fluxo fluvial, a circulação de maré e por ventos mais fortes, que aumentam a abundância destas microalgas em áreas mais rasas. No trabalho de campo, em algumas situações, ocorreram fortes correntes durante a realização das amostragens. Por outro lado, microalgas cêntricas pelágicas são transportadas para o interior da baía pela maré enchente (CREMER et al. 2006).

Microalgas potencialmente nocivas e tóxicas foram registradas no canal do rio Palmital ao longo do estudo, como Coscinodiscus wailesii, Asterionellopsis glaciallis, Chaetoceros spp., Skeletonema costatum, Pseudo-nitzschia spp., Dinophysis sp. e Alexandrium sp. Os quatro primeiros podem ser nocivos quando em grande abundância, com a possibilidade de provocar depleção de nutrientes (SMAYDA, 1997), alteração da cadeia trófica local (ROY et al., 1989), queda no teor de oxigênio (FERNANDES et al., 2001; PROENÇA \& FERNANDES, 2004), mortalidade de organismos filtradores (ODEBRECHT et al., 2002) e danos às brânquias (com possibilidade de morte) de organismos aquáticos (FRYXELL \& VILLAC, 1999). Pseudo-nitzschia spp. possui várias espécies produtoras de ácido domóico, uma neurotoxina que pode ocasionar intoxicação do tipo amnésica (Amnesic Shellfish Poisoning - ASP) (MAFRA et al., 2006). Dinophysis sp. são dinoflagelados considerados potencialmente produtores de toxinas que causam perturbações gastro-intestinais (Diarrhetic Shellfish Poisoning - DSP). O gênero Alexandrium possui espécies potencialmente produtores de toxinas que causam a síndrome conhecida como intoxicação paralisante por moluscos (Paralythic Shellfish Poisoning - PSP), levando, em casos extremos, à paralisia respiratória e morte (CEMBELLA, 1989; HESTER \& HARRISON, 2011). Uma vez que o crescimento destas microalgas é favorecido por vários fatores facilmente encontrados em condições ótimas na área de estudo (e.g. temperatura, salinidade e disponibilidade de nutrientes), existe a possibilidade de desenvolverem florações, com riscos para humanos (via consumo de moluscos), ambiente e organismos aquáticos.
Em síntese, os parâmetros físicos e químicos revelaram uma área com potencial para grande produção primária, porém com indícios de excesso de poluição orgânica. O fitoplâncton variou espaço-sazonalmente em abundância e variedade de táxons, com um episódio de "bloom" para S. costatum. A ocorrência de microalgas potencialmente nocivas e tóxicas chama a atenção para os perigos associados a um possível desequilíbrio ambiental, sendo necessária a intermitente análise de dados na área. Neste sentido, o presente trabalho forneceu um primeiro panorama da área do canal do rio Palmital quanto aos aspectos estudados e devido ao seu caráter pioneiro, permite sugerir mais estudos com novas abordagens, além de um monitoramento ambiental continuo.

\section{Agradecimentos}

A E. Melo pelo auxílio em campo. A B.M.O. Torrens e M. Simm pelo auxílio na análise de nutrientes. Ao apoio estrutural, logístico e financeiro da Universidade da Região de Joinville (Univille) e do Fundo de apoio à Pesquisa da Univille (FAP/Univille) para a viabilização deste trabalho.

\section{Referências}

AVELINE, L.C. 1980. Fauna dos manguezais brasileiros. Revista Brasileira de Geografia 42, p. $786-821$.

BONEY, A.D. 1989. Phytoplankton. 2ed. London, E. Arnold. 118p

BRAGA, E.S. BONETTI, C.V.D.H. BURONE, L. \& BONETTI FILHO, J. 2000. Eutrophication and bacterial pollution caused by industrial and domestic wastes at the Baixada Santista estuarine system - Brazil. Marine Pollution Bulletin 40, p. $165-173$.

BRANDINI, N. 2000. Variação especial e sazonal da produção primária do fitoplâncton em relação às propriedades físicas e químicas na baía das Laranjeiras e áreas adjacentes (complexo estuarino da Baía de Paranaguá - PR/BR). Tese de mestrado. Universidade Federal do Paraná. Curitiba.

BRANDINI, F.P. \& THAMM, C. A. C. 1994. Variação diária e sazonal do fitoplâncton e parâmetros ambientais na baía de Paranaguá. Nerítica, 1 (3):9-19. 
CAMACHO, F.P. \& SOUZA-CONCEIÇÃO. 2007. Distribuição espaço-temporal da clorofila $a$ e das variáveis ambientais em praias estuarinas da ilha de São Francisco do Sul (Baía da Babitonga, sul do Brasil). Boletim Técnico-Científico do CEPENE. Ministério do Meio Ambiente. n 15. 2 p. 9-16.

CAMACHO, F.P. 2006. Variação temporal da biomassa fitoplanctônica e de nutrientes nas águas junto à margem da cidade de São Francisco do Sul na baía da Babitonga (Santa Catarina, Brasil). Trabalho de conclusão de curso, UNIVILLE.

CARMELO, T. R. 1997. Identifying marine diatoms and dinoflagellates. Academic Press. Florida.

CEMBELLA, A.D. 1989. Ocurrence of okadaic acid a major shellfish toxin in natural populations of Dinophysis spp. From the eastern coast of North America. Journal of Applied Phycology, v. 1, p. 307-310.

CERVETO, G.; MESONES, C.; CALLIARI, D. 2002. Phytoplankton biomass and its relationship to environmental variables in a disturbed coastal area of the Rio de la Plata, Uruguay, before the new sewage collector system. Atlântica. 24: 45-54.

CLARKE, K. R.; WARWICK, R. W. 2001.Change in marine communities: an aproach to statistical analysis and interpretation: Plymouth Marine Laboratory.

COSTA, M. D. P. \& SOUZA-CONCEIÇÃO, J. M. Composição e abundância de ovos e larvas de peixes na baía da Babitonga, Santa Catarina, Brasil. Pan-American Journal of Aquatic Science, Rio Grande, v. 4, n. 3, p. 372-382, 2009.

CREMER, J. M., MORALES, R. D. P., OLIVEIRA, M. N. de T. 2006. Diagnostico ambiental da baia da Babitonga, Joinville,SC : UNIVILLE.

DELGADO-NORIEGA, C.; MUNIZ, K.; ARAÚJO, M. C.; TRAVASSOS, R.K. \& NEUMANNLEITÃO, S. 2005. Fluxos de nutrientes inorgânicos dissolvidos em um estuário tropical - Barra das Jangadas, PE, Brasil. Tropical Oceanography, Recife, 33 (2): 129-139.

DENIT/IME. 2004. Estudos Ambientais da Baía da Babitonga - Canal do Linguado. Relatório Final dos Estudos da Baía da Babitonga / Canal do Linguado: Convênio DNIT / IME: CD/ROM.
FATMA - FUNDAÇÃO DO MEIO AMBIENTE DE SANTA CATARINA; KNIE, J.L.W. 2002. Atlas Ambiental da Região de Joinville: Complexo Hídrico da Baía da Babitonga. Joinville, SC: FATMA/GTZ.

FERNANDES, L. F., ZEHNDER-ALVES, L. \& BASSFELD, J. 2001. The recently established diatom Coscinodiscus wailesii (Coscinodiscales, Bacillariophyta) in Brazilian waters. I: remarks on morphology and distribution. Phycol. Res. 49:8996.

FRYXELL, G.R. \& VILLAC, M.C. 1999. Toxic and harmful marine diatoms. In: E.F. STOEMER \& J.P. SMOL. (Eds). The diatoms: applications for the environmental and earth sciences. Cambridge University Press, Cambridge, p. 1-469.

HESTER, R. E. \& HARRISON, R.M. 2011. Marine Pollution and Human Health. London: RSC Publishing, 130p.

IBAMA - INSTITUTO BRASILEIRO DO MEIO AMBIENTE E DOS RECURSOS NATURAIS RENOVÁVEIS. 1998. Proteção e controle de ecossistemas costeiros: Manguezais da baía da Babitonga. Brasília: IBAMA.

KOLASA, J. \& ZALEWSKI, M. 1995. Notes on ecotone attributes and functions. Hydrobiology 303. p. $1-7$.

KUTNER, M.B.B. 1972. Seasonal variation and phytoplankton distribution in Cananéia region, Brasil. Instituto oceanográfico USP, São Paulo, 361. p. 17.

LALLI, C. M \& PARSONS, T.R, 1997. Biological oceanography: an introduction. $2^{\circ} \mathrm{ed}$. Oxford. Butterworth-Heinemann.

LAPOINTE, B.E. \& CLARK, M.W. 1992.

Nutrient imput from the watershed and coastal eutrophication in the Florida Keys. Estuaries. Lawrence, p. 465-476.

MAFRA, L. L. JR.; FERNANDES, L. F. \& PROENÇA, L. A. O. 2006. Harmful algae and toxis in Paranaguá bay, Brazil: bases for monitoring. Brazilian journal of oceanography. Vol.54 no.2-3 São Paulo. 
McLUSKY, D. S. 1994. The estuarine ecosystem. New York: Chapman \& Hall. 215 p.

ODEBRECHT, C.; MÉNDEZ, S. \& GARCIA, V.M.T. 2002. Floraciones de microalgas nocivas em Brasil: estado del arte y proyectos en curso. In: E. A. SAR; M.E. FERRARIO \& B. REGUERA. (Eds), Floraciones Algales Nocivas en el Cono Sur Americano. Vigo: Instituto Español de Oceanografia, p. 219-233.

ODUM, E.O. 1983. Ecologia. Rio de Janeiro: Guanabara, 434p.

PROENÇA, L.A.O. \& FERNANDES, L.F. 2004. Introdução de microalgas no ambiente marinho: impactos negativos e fatores controladores. In Água de lastro e bioinvasão (J. S. V. Silva \& R.C.C.L Souza, eds). Editora Interciência, Rio de Janeiro, p.1-224.

RAYMONT, J.E.G. 1980. Plankton and Productivity in the Oceans. Volume-1 Phytoplankton.

Pergamon Press, 489p.

ROY, S.; HARRIS, R.P. \& PULET, S.A. 1989. Inneficient feeding by Calanus helgolandicus and Temora longicornis on Coscinodiscus wailesii: Quantitative estimation using chlorophyll-type pigment and effects on dissolved free amino acid. Marine Ecology. Prog. 52, p. 145-153.

SEELIGER, U.; ODEBRECHT, C. \& CASTELLO J.P. 1998. O ecossistema costeiro e marinho do extremo sul do Brasil. Rio Grande: Editora Ecoscientia.

SMAYDA, T.J. 1997. Harmful algae blooms: their ecophysiology and general relevance to phytoplankton blooms in the sea. Limnology and Oceanography. V. 42. P. 1137 - 1153.

SOUZA-CONCEIÇÃO, J.M. 2008. Praias estuarinas como habitat de criação para estágios iniciais de peixes na ilha de São Francisco do Sul (Baía da Babitonga, Santa Catarina). Tese de doutorado. Universidade Federal do Paraná. Curitiba.

STATSOFT, 1995. STATISTICA for Windows (Computer program manual). Tulsa: StatSoft.

STEIDINGER, K. A. \& JANGEN, K. (1996). Dinoflagellates, p.387-584. In: CARMELO, T. R. (1997). Identifying marine diatoms and dinoflagellates. Academic Press. Florida. 